\title{
Helicobacter pylori eradication in the management of idiopathic pulmonary fibrosis
}

\section{To the Editors:}

Idiopathic pulmonary fibrosis (IPF) is a relentlessly progressive disease of unknown aetiology. Current theory regarding the pathogenesis of IPF suggests that recurrent exposure of the lungs to repeated injury and/or antigen of "unknown origin" leads to the release of pro-fibrotic growth factors and fibrosis [1]. The nature of the triggering injury and/or antigen remains a mystery. A number of studies have documented high prevalence of gastro-oesophageal reflux disease (GERD) in patients with IPF in up to $90 \%$ of patients $[2,3]$. This has led to the assumption that recurrent micro-aspiration of acid droplets causes, or contributes to, the recurrent insults to the lungs and the development of IPF [2]. However, the prevalence of GERD in the general population (10-20\%) far exceeds the prevalence of IPF (13-20 cases per 100,000 population) [4,5]. So, if the acid content of the reflux is the probable triggering/injurious agent, then what makes only a small proportion of subjects with GERD develop IPF? Recent meta-analysis and epidemiological data have shown that high prevalence of GERD is associated with low Helicobacter pylori prevalence status [6]. This may raise the hypothesis that IPF only develops in those patients with GERD whose gastric juice contains $H$. pylori [7]. Put simply, IPF may result from micro-aspiration of gastric contents due to GERD, but only in the small proportion of patients with GERD who have H. pylori in their gastric juice.

Attempting to explain the development of IPF in individuals with GERD merely in terms of the chemical composition of the gastric content (acid content) or a genetic predisposition is not rewarding, because the chemical composition of gastric juice is probably similar in all individuals with GERD and no correlation between the severity of IPF and the severity of GERD was found in previous studies [2]. In addition, no specific genetic markers have been identified in patients with IPF [8]. Therefore, these assumptions cannot explain the low prevalence of IPF among the general population, despite a high prevalence of GERD.

Proton pump inhibitor (PPI) therapy has been shown to stabilise lung function in some patients with IPF. Previously, this effect was attributed to the acid suppression action of PPI, but it should be noted that PPI therapy does not prevent acid reflux. More importantly, PPIs have been found to exert a bacteriostatic effect on $H$. pylori, interfere with the bacterial energy production and cause a decrease in antral $H$. pylori density during therapy $[9,10]$. Another important reason to justify testing the role of $H$. pylori hypothesis is that a noninvasive, simple, highly sensitive and specific test is available to detect the presence of $H$. pylori, which is the "H. pylori faecal antigen test" with sensitivity and specificity of up to 98 and $94 \%$, respectively [11]. This test may be used to detect the prevalence of $H$. pylori infection in patients with IPF and compare it with control groups from patients with other lung diseases and healthy individuals. If the prevalence of $H$. pylori in IPF patients is found to be high, the next step will be the detection of $H$. pylori in bronchoalveolar lavage of these patients.

I think this hypothesis is a fertile area for future research and, if it proves true, prevention and treatment of a relentlessly progressive disease will be in hand.

\section{W.H. Ibrahim}

*Pulmonary Division, Dept of Medicine, Hamad General Hospital, Doha, Qatar.

\section{STATEMENT OF INTEREST}

None declared.

\section{REFERENCES}

1 Strieter RM. Pathogenesis and natural history of usual interstitial pneumonia: the whole story or the last chapter of a long novel. Chest 2005; 128: Suppl. 1, 526S-532S.

2 Raghu G, Freudenberger TD, Yang S, et al. High prevalence of abnormal acid gastro-oesophageal reflux in idiopathic pulmonary fibrosis. Eur Respir J 2006; 27: 136-142.

3 Tobin RW, Pope CE, Pellegrini CA, Emond MJ, Sillery J, Raghu G. Increased prevalence of gastroesophageal reflux in patients with idiopathic pulmonary fibrosis. Am J Resp Crit Care Med 1998; 158: 1804-1808.

4 Dent J, EL-Serag HB, Wallander MA, Johansson S. Epidemiology of gastro-oesophageal reflux disease: a systematic review. Gut 2005; 54: 710-717.

5 American Thoracic Society. Idiopathic pulmonary fibrosis: diagnosis and treatment. International Consensus Statement. American Thoracic Society (ATS), and the European Respiratory Society (ERS). Am J Respir Crit Care Med 2000; 161: 646-664.

6 Cremonini F, Di Caro S, Delgado-Aros S, et al. Metaanalysis: the relationship between Helicobacter pylori infection and gastro-oesophageal reflux disease. Aliment Pharmacol Ther 2003; 18: 279-289.

7 Ibrahim WH, Raza T. Helicobacter pylori: could it be the missing piece of the puzzle? JMJ 2007; (In Press).

8 Raghu G, Mageto YN. Genetic predisposition of interstitial lung diseases. In: King TE Jr, Schwartz MI, eds. Interstitial Lung Diseases. 3rd Edn. Hamilton, B.C. Decker, 1998; p. 119-132.

9 Suerbaum S, Leying H, Memmerle B, Klemm K, Opferkuch W. Antibacterial activity of pantoprazole, 
omeprazole and other $\mathrm{H}+/ \mathrm{K}+-\mathrm{ATPase}$ inhibitors against Helicobacter pylori. Rev ESP Enf Digest 1990; 78: P256.

10 Suerbaum S, Leying $\mathrm{H}$, Klemm K, Opferkuch W. Antibacterial activity of pantoprazole and omeprazole against Helicobacter pylori. Eur J Clin Microbiol Infect Dis 1991; 10: 92-93.
11 Vaira D, Malfertheiner P, Megraud F, et al. Diagnosis of Helicobacter infection with a new non-invasive antigen-based assay. HpSA European study group. Lancet 1999; 354: 30-33.

DOI: $10.1183 / 09031936.00033907$

\section{Origin of the term XDR-TB}

\section{To the Editors:}

MigLIORI et al. [1] have written a commendable editorial about the challenges to science presented by the emergence of extensively drug-resistant tuberculosis (XDR-TB) as a named entity. We wish to clarify the origin and development of the term "XDR-TB".

As noted by MigLIORI et al. [1], resistance to second-line drugs is not a new phenomenon. Despite years of anecdotal reports about "super bugs" and TB strains (predominantly in the former Soviet Union and Asia) with resistance to six, seven and eight or more anti-TB drugs, the global distribution of TB strains with concurrent resistance to multiple second-line drugs had not been previously reported.

The concept and term XDR-TB as a distinct nosological entity were first developed by the Centers for Disease Control and Prevention (CDC) in March 2005 and were introduced into public use in October 2005 at the 36th World Conference on Lung Health in Paris, France [2,3]. At that meeting, data on second-line drug resistance from a joint global survey of Supranational TB Reference Laboratories conducted by the CDC and the World Health Organization (WHO), as well as treatment outcomes of XDR-TB patients in Latvia, were first presented using the working definition later published in 2006. Shortly thereafter, a cluster of TB deaths with resistance to multiple second-line drugs (called "highly drug-resistant $\mathrm{TB}^{\text {" }}$ by the scientists) in HIV-infected persons in rural KwaZuluNatal, South Africa, was presented at the 13th Conference on Retroviruses and Opportunistic Infections (Denver, CO, USA) in February 2006 [4]. At the time and for reasons that are unclear, this report did not reach the attention of the global public health community, perhaps because this new "entity" in TB control had not yet been given a new name. Shortly thereafter, the original definition for XDR-TB was first published in March 2006 [5]; it was later revised in October 2006 at an emergency meeting of the Global Task Force on XDR-TB and posted on the WHO website. The revised definition was simultaneously published in November 2006 in the Morbidity and Mortality Weekly Report [6] and in the WHO's Weekly Epidemiologic Record [7].
T.H. Holtz and J.P. Cegielski

CDC, Division of TB Elimination, Atlanta, GA, USA.

\section{STATEMENT OF INTEREST}

None declared.

\section{REFERENCES}

1 Migliori GB, Loddenkemper R, Blasi F, Raviglione MC. 125 years after Robert Koch's discovery of the tubercle bacillus: the new XDR-TB threat. Is "science" enough to tackle the epidemic? Eur Respir J 2007; 29: 423-427.

2 Shah NS, Wright A, Drobniewski F, et al. Extreme drug resistance in tuberculosis (XDR-TB): global survey of supranational reference laboratories for Mycobacterium tuberculosis with resistance to second-line drugs. Int $J$ Tuberc Lung Dis 2005; 9: Suppl. 1, S77.

3 Holtz TH, Riektsina V, Zarovska E, Laserson KF, Wells CD, Leimane V. XDR-TB: extreme drug-resistance and treatment outcome under DOTS-Plus, Latvia, 2000-2002. Int J Tuberc Lung Dis 2005; 9: Suppl. 1, S258.

4 Moll A, Gandhi NR, Pawinski R, et al. Identification of a multidrug-resistant tuberculosis cluster as a cause of death among HIV co-infected patients in rural South Africa. 13th Conference on Retroviruses and Opportunistic Infections, Denver, CO, USA. February 7, 2006, Poster O-115.

5 Centers for Disease Control and Prevention (CDC). Emergence of Mycobacterium tuberculosis with extensive resistance to second-line drugs - worldwide, 2000-2004. MMWR Morb Mortal Wkly Rep 2006; 55: 301-305.

6 Centers for Disease Control and Prevention. Notice to readers: revised definition of XDR-TB. MMWR Morb Mortal Wkly Rep 2006; 55: 1176.

7 World Health Organization. Extensively drug-resistant tuberculosis (XDR-TB): recommendations for prevention and control. Wkly Epidemiol Record 2006; 81: 430-432. 